\title{
Multimodality imaging of a paediatric pancreatic fracture
}

\author{
Sankar Neelakantan, Warun Jose, Soumya Cicilet, Asthik Biswas
}

Department of Radiology, St Johns Medical College Hospital, Bangalore, Karnataka, India

\section{Correspondence to} Dr Sankar Neelakantan, dr.sankar@live.com

Accepted 2 May 2016

\section{DESCRIPTION}

A 13-year-old boy presented to the emergency department, with a history of blunt abdominal trauma. On examination, epigastric tenderness with regional guarding was noted. His vitals were stable. An initial screening transabdominal ultrasound showed a linear fracture (parenchymal disruption) of the pancreatic neck with minimal peripancreatic fluid (figure 1). Contrast-enhanced CT of the abdomen showed the fracture extending anteroposteriorly with minimal peripancreatic fluid. There was no other associated visceral injury (figures 2-4). An MRI with MR cholangiopancreatography (MRCP) was performed 2 days later, which confirmed pancreatic duct disruption and showed the peripancreatic fluid collection tracking along the

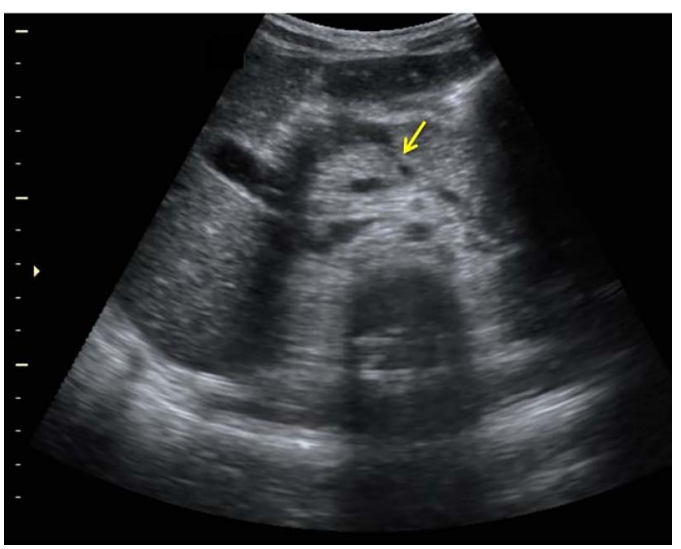

Figure 1 Upper abdominal transverse view of the pancreas on transabdominal ultrasonography shows a linear fracture (parenchymal disruption) of the neck (arrow) extending anteroposteriorly with minimal peripancreatic fluid.

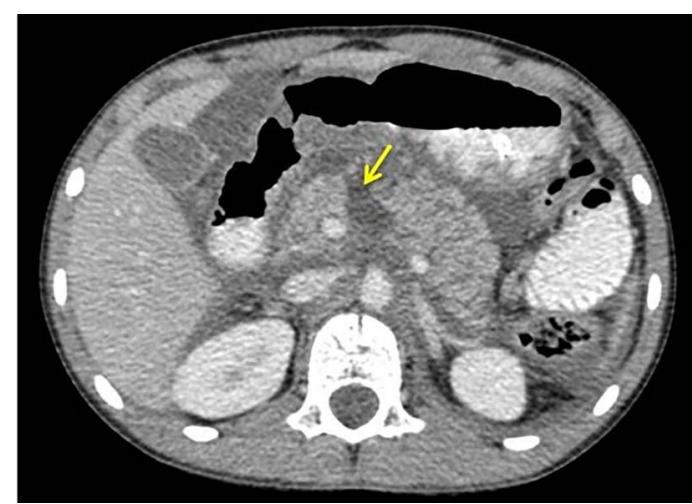
Year] doi:10.1136/bcr-2016-
Figure 2 Axial contrast-enhanced CT section of the pancreas showing parenchymal disruption of the neck of the pancreas (arrow).
Jose W, Cicilet $\mathrm{S}$, et al. BM Case Rep Published online: [please include Day Month 215708

CrossMark posteromedial aspect of the liver (figures 5-8). The patient was classified as having grade III pancreatic injury as per the American Association for the Surgery of Trauma (AAST) classification. ${ }^{1}$ The patient underwent surgical intervention.

Blunt abdominal trauma rarely results in pancreatic fracture $(<2 \%$ cases) by virtue of the pancreas being protected in its retroperitoneal location. When present, pancreatic fractures are associated with high morbidity and mortality. This is especially true when the diagnosis is delayed and in the presence of associated ductal injury. ${ }^{2}$ Symptoms

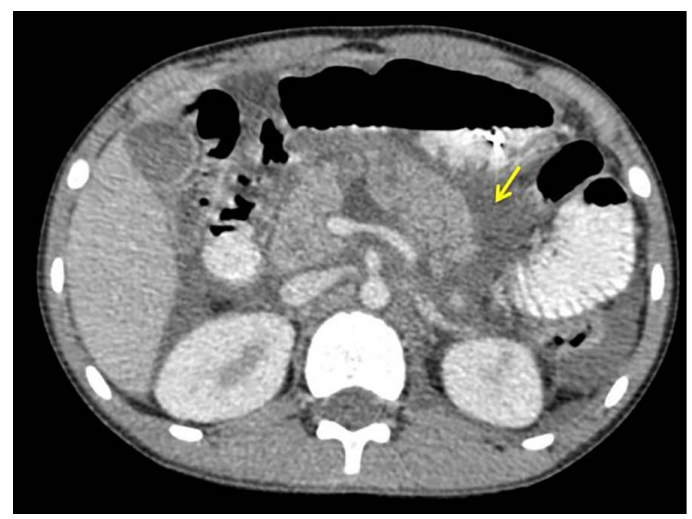

Figure 3 Axial contrast-enhanced CT section of the pancreas showing focal peripancreatic fluid collection (arrow).

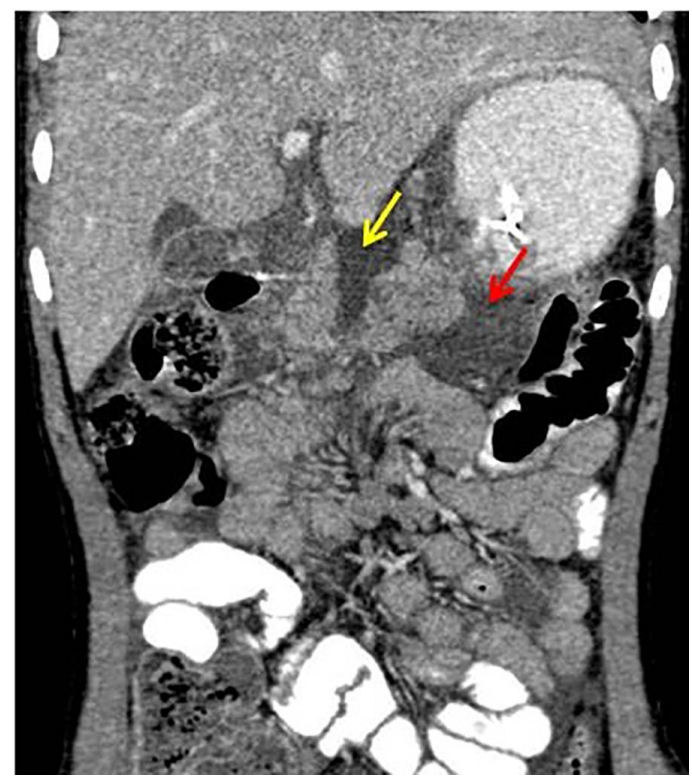

Figure 4 Coronal contrast-enhanced CT image showing superior extension of the parenchymal rent (yellow arrow) and peripancreatic fluid collection (red arrow). 


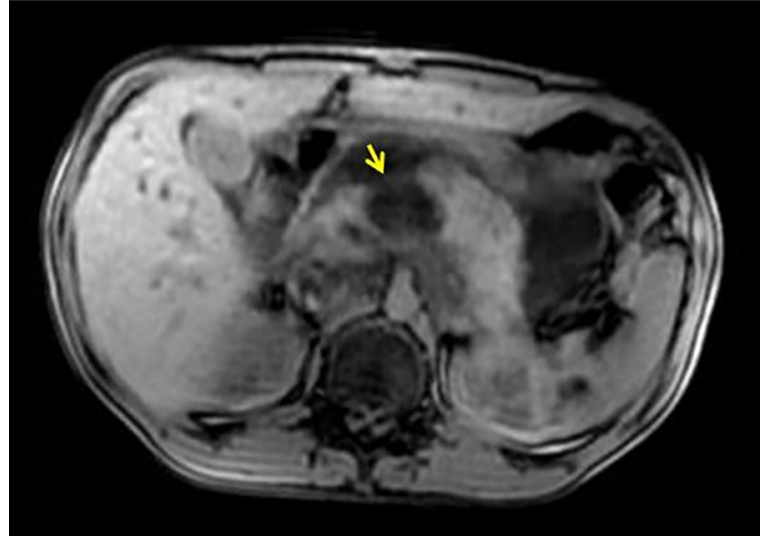

Figure 5 T1-weighted axial MRI of the pancreas showing evidence of parenchymal laceration (arrow).

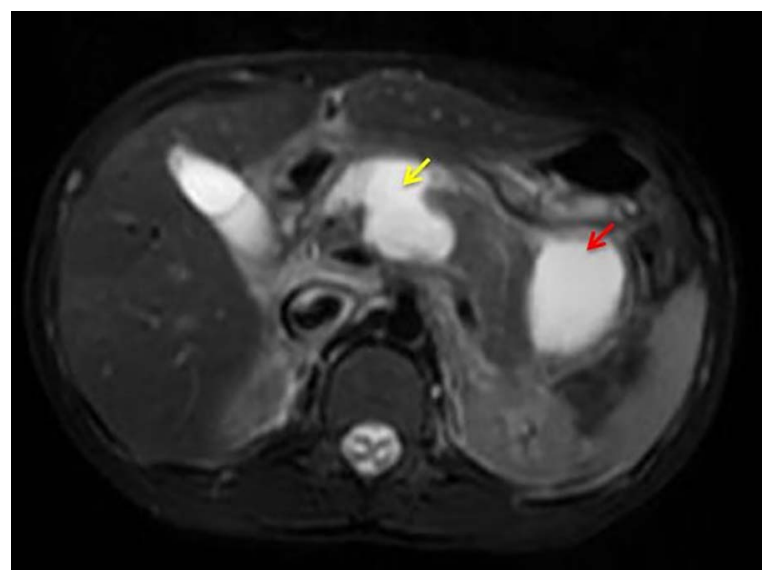

Figure 6 T2-weighted axial MRI of the pancreas shows evidence of parenchymal laceration (yellow arrow) with peripancreatic fluid collection (red arrow).

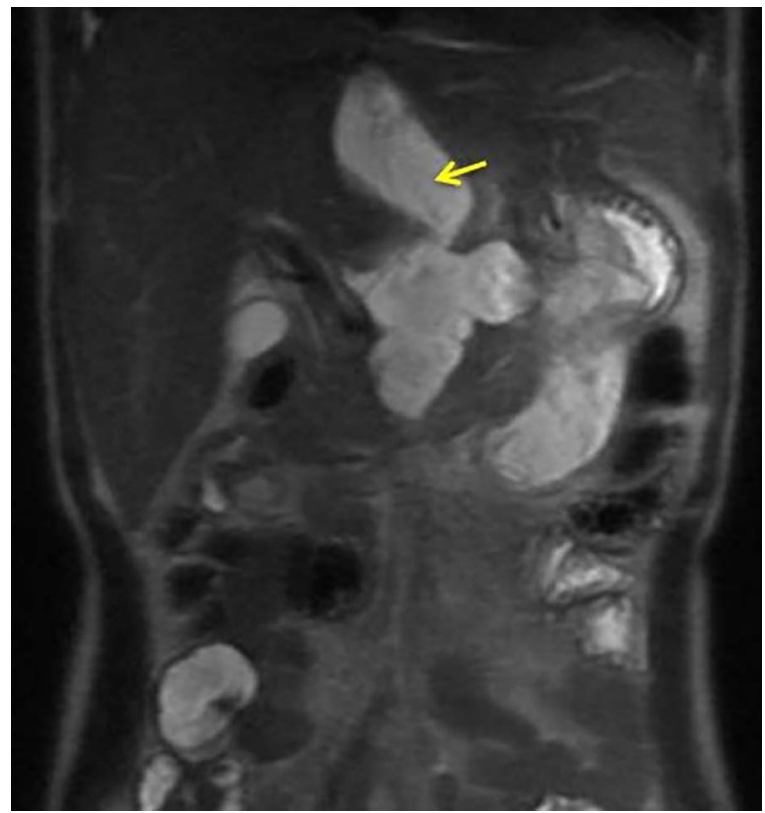

Figure 7 T2-weighted coronal MRI showing the superior extension of the peripancreatic fluid collection (arrow).

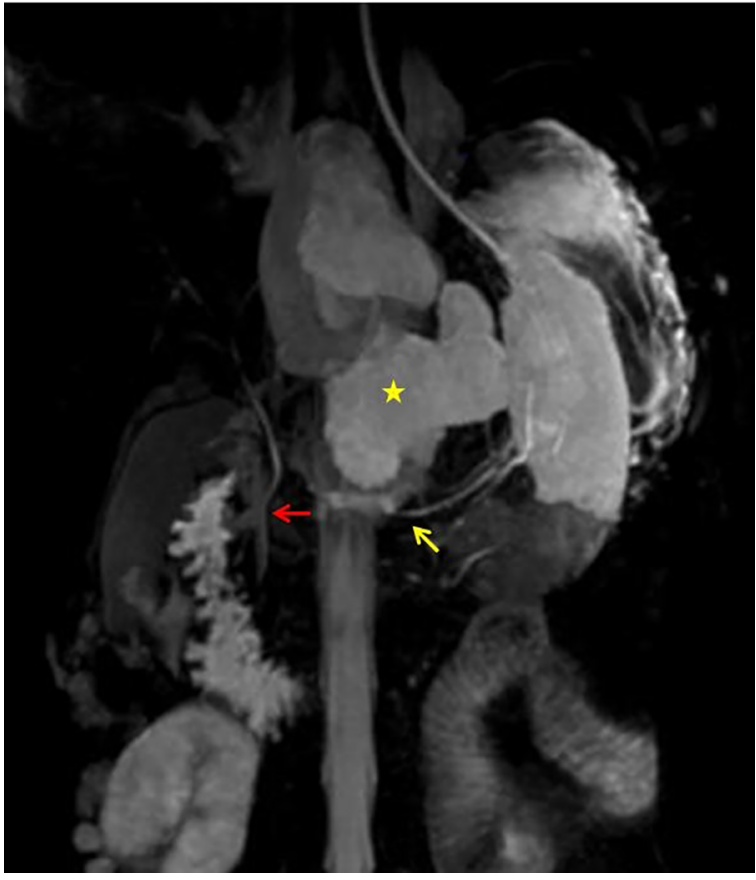

Figure 8 Projection coronal MR cholangiopancreatography image showing mid-pancreatic duct disruption (yellow arrow) resulting in peripancreatic fluid collection (star). The red arrow denotes the common bile duct.

and clinical findings are usually non-specific, and biochemical and imaging is essential. Traumatic pancreatic injury most commonly affects the body of the pancreas (in about $67 \%$ of cases).

Direct imaging signs include visualisation of the fracture line (parenchymal laceration), comminution, ductal discontinuity and parenchymal swelling. Indirect imaging signs include peripancreatic fat stranding, fluid collections and pseudocysts.

The imaging modality for initial imaging is usually a contrast-enhanced CT. MRCP can be performed 2-3 days later to assess ductal continuity and size of the peripancreatic collection, if any. ${ }^{3}$

\section{Learning points}

- Although rare, blunt abdominal trauma can result in pancreatic parenchymal and/or ductal disruption.

- Assessing duct disruption is of vital importance in prognostication. If present, there is a minimal role for conservative management.

- Cross-sectional imaging features of pancreatic fractures include visualisation of the fracture line (parenchymal disruption), ductal discontinuity, pancreatic parenchymal swelling, peripancreatic fat stranding and peripancreatic fluid collections.

- MR cholangiopancreatography is useful to demonstrate pancreatic ductal injury.

Twitter Follow Sankar Neelakantan at @drsankar23

Contributors SN contributed to the study concept and drafting. WJ participated in the literature review. $A B$ participated in the editing of the manuscript. SC approved the final draft submitted for publication. 
Competing interests None declared.

Patient consent Obtained.

Provenance and peer review Not commissioned; externally peer reviewed.

\section{REFERENCES}

1 Campbell R, Kennedy T. The management of pancreatic and pancreaticoduodenal injuries. Br J Surg 1980;67:845-50.

2 Cirillo RL, Koniaris LG. Detecting blunt pancreatic injuries. J Gastrointest Surg 2002;6:587-98.

3 Belo-Oliveira P, Rodrigues H, Belo-Soares P, et al. Pancreatic fracture. 2005.

Copyright 2016 BMJ Publishing Group. All rights reserved. For permission to reuse any of this content visit http://group.bmj.com/group/rights-licensing/permissions.

BMJ Case Report Fellows may re-use this article for personal use and teaching without any further permission.

Become a Fellow of BMJ Case Reports today and you can:

- Submit as many cases as you like

- Enjoy fast sympathetic peer review and rapid publication of accepted articles

- Access all the published articles

- Re-use any of the published material for personal use and teaching without further permission

For information on Institutional Fellowships contact consortiasales@bmjgroup.com

Visit casereports.bmj.com for more articles like this and to become a Fellow 